\title{
La revocatoria como mecanismo constitucional de participación política ante la pérdida de confianza del parlamento peruano.
}

\author{
The revocation as a constitutional mechanism of political participation at the loss of confidence of the peruvian \\ parliament
}

\section{Lourdes Pamela Meza Vásquez'}

\section{RESUMEN}

Objetivo: Plantear la revocatoria de los congresistas, con el fin de que el mandato parlamentario pueda ser acortado y que su gestión pueda estar sometida a control de manera más frecuente; de modo que no tengamos que soportar a un mal representante los cinco años que dure su mandato.

Método: Uso del método deductivo, estando enmarcada en el tipo de investigación aplicada y fundamentada a nivel explicativo. Se han utilizado técnicas e instrumentos de recolección de datos, específicamente el análisis de fuentes documentales y la encuesta, la misma que se realizó en la ciudad de Tacna, y con la cual se dio cumplimiento a mis objetivos planteados y a la comprobación de mis hipótesis.

Resultados: Se obtuvo el $90 \%$ de aprobación a la introducción de la revocatoria de los congresistas peruanos y un $10 \%$ que no lo aprueba.

Conclusiones: Ante la pérdida de confianza de nuestro parlamento peruano, será necesario introducir la revocatoria, como mecanismo constitucional de participación política, con el fin de fortalecer la democracia, que es lo que caracteriza a todo estado de derecho.

\section{PALABRAS CLAVES}

Participación Política, Representación, Participación, Revocación, Revocatoria.

\begin{abstract}
Objective: Pose the revocation of Congress, in order that the parliamentary mandate can be shortened and that its management can be subject to in a more frequent monitoring, so that we do not have to put up with a bad representative the five year term of government.
\end{abstract}

Method: Use of the deductive method, being framed in the type of applied research and substantiated explanatory level, having used techniques and data collection instruments, specifically the analysis of documentary sources and the survey, the same as was done in the city of Tacna, and which complied with my objectives and my hypothesis testing.

Results: We obtained $90 \%$ of adoption to the introduction of the revocation of the Peruvian Congress and $10 \%$ do not approve.

Conclusions:That the loss of confidence of our Peruvian parliament, the revocation be necessary to introduce as a constitutional means of political participation in order to strengthen democracy, which is what we characterizes every rule of law.

\section{KEYWORDS}

Political Participation, Representation, Participation, Revocation, Revocation.

1. Magíster en Derecho Constitucional, Abogada. Actualmente labora en el Poder Judicial - Secretaria del Juzgado de Paz Letrado Laboral. Especializada en Derecho Constitucional.

E-mail: pamela_meva@hotmail.com 


\section{Introducción}

Esta Investigación científica fue el producto de la confrontación con nuestra lamentable realidad política.

Por supuesto que no es mi intención expresar opinión personal, sino la de la colectividad. Como es sabido, en campaña electoral ésta se siente fascinada y cautivada por las promesas de sus candidatos; en campaña electoral la euforia congresal nos contagia y es ahí cuando nuestra vida se ve clara al sentirnos comprendidos por nuestros candidatos al parlamento peruano; pero pasa luego tiempo, los anuncios no se cumplieron, los hechos mantuvieron su tristeza, su injusticia; y es ahí cuando confundidos y acongojados nos replegamos al sentirnos utilizados por nuestros candidatos. Nuestros representantes al llegar al poder se empapan tanto de éste que les produce amnesia, olvidándose de la ciudadanía que fue quien le delegó el poder.

Pero como se dice: "no hay mal que dure cien años ni cuerpo que lo resista", sostengo que podemos ver y sentir que existe "la luz al final del túnel". Entonces, siendo esa luz la que debemos encontrar, mi propuesta materializada en el presente trabajo de investigación, es plantear la revocatoria de los parlamentarios, siendo esa la llave que abrirá las puertas de la esperanza de todos los ciudadanos peruanos.

En ese entender, con mi investigación científica demostraré que con la revocatoria del mandato congresal, ejerceremos efectivamente nuestro derecho constitucional de participación política, pues así como hemos dado poder (con nuestros votos) a nuestros congresistas, lo mas justo será, que cuando hayamos perdido la confianza en ellos, tengamos el derecho de revocar el poder concedido.

En las últimas décadas, el sistema político peruano viene atravesando una severa crisis de representación, que habiéndose iniciado en la década de los 90 , no tiene cuando acabar.

La situación es grave, nuestros congresistas expiden normas inadecuadas a la realidad, que no son mas que normas con nombre propio, ellos se dejan manipular por la clase alta, no efectuando una buena legislación en favor del estado peruano, situación que ha traído como consecuencia poco desarrollo económico y social al pueblo que los eligió.
Es evidente, los escándalos que algunos de sus miembros han sumido al parlamento en un profundo descrédito, "la roba cable", "el come oro", "la lava pies", "el mata perro", "el come pollo", entre otros, son congresistas que no justifican su sueldo, pues son personajes que no producen o no han producido desarrollo; por ello que, el Congreso de la República, requiere de un cambio radical urgente porque es una institución muy desprestigiada y la ciudadanía está cansada de los escándalos registrados en el parlamento, por lo que es sumamente necesario cambiar esa imagen.

En efecto, lo que realmente respalda la opinión pública es la idea de que el mandato de los parlamentarios debe poder ser acortado y que su gestión pueda estar sometida a control de manera más frecuente; de modo que no necesariamente los electores tengan que soportar a un mal representante los cinco años que dura actualmente el mandato parlamentario. Si el poder viene del pueblo, el mismo que es conferido por los ciudadanos a los representantes a través del sufragio, lo democrático es que los ciudadanos tengan un mayor control sobre la representación que otorgan. En ese sentido, es más democrático que los ciudadanos, quienes han otorgado el mandato que detentan sus representantes al congreso, puedan incluso revocar dicho mandato cuando hayan perdido su total confianza.

Por ello, el mecanismo que permitiría esa evaluación de los representantes por parte de sus electores, pudiendo sancionarlos con el recorte de su mandato, es la revocatoria.

La Constitución ha establecido en su artículo $31^{\circ}$ los mecanismos de participación política, que permiten que la ciudadanía pueda participar en los asuntos públicos mediante referéndum; iniciativas legislativas; remoción o revocación de autoridades y demanda de rendición de cuentas; bajo ese precepto constitucional, es que si partimos de la premisa que la Carta Magna contempla la revocatoria de autoridades y teniendo bien en claro que un congresista es una autoridad, también tendrían que ser revocados.

Es entonces que, dicha deducción, derivada de un silogismo, sirve de sustento para formular mi propuesta de reforma constitucional, la misma que busca incorporar en la Constitución Política la revocatoria del mandato congresal, a fin que todas nuestras autoridades de elección popular se encuentren a la luz del principio de la 
igualdad, y que de ese modo la ciudadanía pueda ejercer plenamente su derecho constitucional de participación política.

Propuesta que se conseguirá modificando el artículo $95^{\circ}$ de nuestra Constitución Política, con el fin de que se incluya la revocatoria del mandato de los congresistas, como mecanismo constitucional de participación política, ante la pérdida de confianza del parlamento peruano, mecanismo que, a fin de cuenta, contribuirá a fortalecer la democracia, que es lo que caracteriza a todo estado de derecho.

\section{Materiales y métodos}

El método que apliqué en mi investigación científica fue el deductivo por cuanto el fenómeno particular que analicé guarda correspondencia con una verdad general ya conocida, verdad que se obtuvo de la aplicación de los instrumentos de recolección de datos; habiendo aplicado la investigación de campo, a través de la encuesta, la cual conllevó a que se reflejara el sentir de la ciudadanía peruana.

\section{Resultados}

Por ser este un artículo científico, el cual se encuentra limitado a un número reducido de hojas para redactarlo, sólo presentaré una circular, la cual hará referencia a la pregunta principal efectuada en mi encuesta, la cual confirmó mi hipótesis(Ver figura №1).

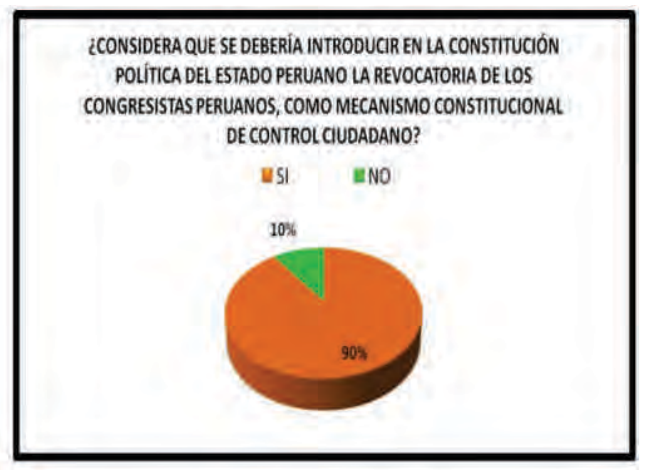

Figura $N^{\circ} 1$

En ese sentido, tras haber aplicado la investigación de campo logré confirmar mi hipótesis, demostrando que resulta necesario incorporar en la Constitución Política del Estado la revocatoria de los congresistas, como mecanismo constitucional de participación política; demostrando además que la pérdida de confianza en el parlamento peruano se debe a que los congresistas asumen con desinterés y negligencia sus funciones, abusan del poder, incurren en actos de nepotismo, no tienen capacidad para dialogar o escuchar, incumplen sus de promesas de campaña, se ausentan frecuentemente a las sesiones del Parlamento, no formulan proyectos de ley, no justifican su sueldo, expiden normas con nombre propio, y porque son poco calificados para asumir tan alto cargo de representación. Indicadores que no hacen más que comprobar que la ciudadanía peruana exige que el mandato parlamentario deba ser acortado cuando hayamos perdido la confianza en nuestros representantes al congreso.

\section{Discusión}

- Lo que realmente respalda la opinión pública es la idea de que el mandato de los parlamentarios debe poder ser acortado y que su gestión pueda estar sometida a control de manera más frecuente; de modo que no necesariamente los electores tengan que soportar a un mal representante los cinco años que dura actualmente el mandato parlamentario.

- Si el poder viene del pueblo, el mismo que es conferido por los ciudadanos a sus representantes a través del sufragio, lo democrático es que los ciudadanos tengan un mayor control sobre la representación que otorgan; de tal forma, será más democrático que los ciudadanos, puedan revocar dicho mandato cuando hayan perdido su total confianza.

- Con la revocatoria ejerceremos efectivamente nuestro derecho constitucional de participación política, pues así como hemos dado poder (con nuestros votos) a nuestros congresistas, también tenemos derecho de revocar ese poder concedido.

- La revocatoria actuaría como una válvula legal que ejercería la ciudadanía, con el fin de que ella misma acorte la representación congresal cuando haya perdido su confianza por una inadecuada representación durante su ejercicio. 
- La Constitución ha establecido en su artículo $31^{\circ}$ los mecanismos de participación política, que permiten que la ciudadanía pueda participar en los asuntos públicos mediante referéndum; iniciativas legislativas; remoción o revocación de autoridades y demanda de rendición de cuentas. Bajo ese precepto constitucional, es que si partimos de la premisa que la Carta Magna contempla la revocatoria de autoridades y teniendo bien en claro que un congresista es una autoridad, los congresistas también tendrían que ser revocados, a fin que todas nuestras autoridades de elección popular se encuentren a la luz del principio de la igualdad, y que de ese modo la ciudadanía pueda ejercer plenamente su derecho constitucional de participación política.

- La revocatoria es un mecanismo de control ciudadano de sus autoridades de elección popular, que tiene la categoría de un Derecho Fundamental, consagrado en la Constitución.

- La revocatoria a los congresistas peruanos tendrá como única finalidad, hacer efectivo el principio de responsabilidad política de los funcionarios públicos, impidiendo al congresistas que haya perdido la confianza del electorado mantenerse en su cargo hasta el final del mandato; sin perjuicio de que si su actuación es generadora de responsabilidad penal, la misma que independientemente se deducirá ante los tribunales respectivos.

- La presente investigación se justifica porque, el tema materia de tesis, se encuentra fundamentado en la necesidad de una reforma constitucional, buscando modificar el artículo $95^{\circ}$ de nuestra Constitución Política, con la finalidad de incorporar la revocatoria del mandato congresal, a fin de que la ciudadanía pueda ejercer el derecho político de revocar a las autoridades de más alta jerarquía del país, electas mediante el voto popular; con el fin de perfeccionar el mecanismo de participación política contenido en el artículo $2^{\circ} 17$, y en el artículo $31^{\circ}$ de nuestra Carta Magna.
- En ese sentido, de aplicarse la revocatoria para los congresistas, esta debería efectuarse bajo las mismas reglas de la revocatoria para los alcaldes y autoridades regionales; $y$ en efecto, proponiendo que la reforma constitucional debiera ser la siguiente:

LEY DE REFORMA CONSTITUCIONAL QUE
ESTABLECE LAREVOCATORIA AL CARGO DE
CONGRESISTA DE LA REPUBLICA
Articulo $1^{\circ}$. Reforma del articulo $95^{\circ}$ de la
Constitución Politica
Modifiquese el articulo 95 de la Constitución Politica
el mismo que queda redactado de la siguiente
manera:
"Articulo 95
El mandato legislativo es imenunciable. Es revocable
pordecisión popular conforme a ley.
Las sanciones disciplinanas que impone el Congreso
a los representantes y que implican suspensión de
funciones no pueden exceder de ciento veinte dias de
legislatura.
La revocatoria procede con la votación de más de
la mitad de los electores del distrito electoral
correspondiente, sin computar los votos blancos y
viciados. No procede en el primer ni en el último
año del mandato. Tampoco es procedente más de
una petición de revocatoria durante un periodo
parlamentario."
Articulo 2 . Disposiciones Derogatorias y
Modificatorias
Deróguense y modifiquense las normas que se
opongan a la presente ley.

\section{Referencias bibliográficas}

1. Pasquino, Gianfranco. Manual de Ciencia Política. Madrid. Alianza Editorial. 1994.

2. Fernández de Mantilla, Lya. Algunas Aproximaciones a la Participación Política. Revista Reflexión Política. Año № 1. Colombia. 1999.

3. Diccionario de Ciencia Política. Alianza Editorial 1980. p. 543.

4. Merino, Mauricio. La Participación Ciudadana en la Democracia. Instituto Federal Alemán. Cuadernos de Divulgación de la Cultura Democrática № 4. México.

5. Cabanellas, Guillermo. Diccionario de Derecho Usual, t. III, Buenos Aires, Editorial Heliasta, $11^{a}$ ed., 1976, p. 598. 
6. Cabanellas, Guillermo. Diccionario de Derecho Usual, t. III, Buenos Aires, Editorial Heliasta, $11^{\text {a }}$ ed., 1976, p. 601.

\begin{tabular}{|c|}
\hline Recibido: $24 / 09 / 13$ \\
Aceptado para publicación: \\
$04 / 11 / 2013$ \\
\hline
\end{tabular}

